\title{
Preliminary results of prognostic significance of proliferating cell nuclear antigen expression in advanced primary larynx carcinomas and lymph node metastases
}

Krzysztof Kupisz ${ }^{1}$, Andrzej Stepulak ${ }^{2,3}$, Małgorzata Zdunek ${ }^{4}$, Janusz Klatka ${ }^{5}$

\begin{abstract}
${ }^{1}$ Department of Otolaryngology and Head and Neck Surgery, Specialist District Hospital, Lublin, Poland

${ }^{2}$ Department of Biochemistry and Molecular Biology, Medical University, Lublin, Poland ${ }^{3}$ Department of Otolaryngology, MSWiA Hospital, Lublin, Poland

${ }^{4}$ Chair and Department of Clinical Pathology, Medical University, Lublin, Poland

${ }^{5}$ Department of Otolaryngology, Medical University, Lublin, Poland
\end{abstract}

Submitted: 2 February 2009

Accepted: 12 March 2009

Arch Med Sci 2010; 6, 1: 65-70

DOI 10.5114/aoms.2010.13509

Copyright $\odot 2010$ Termedia \& Banach

\begin{abstract}
Introduction: The aim of this study was to investigate the prognostic significance of proliferating cell nuclear antigen (PCNA) expression in laryngeal carcinoma in relation to clinicopathological features. Special emphasis was placed on examining the relationship of PCNA expression in the primary tumour and PCNA expression in corresponding lymph node metastases obtained from the same patients.

Material and methods: The study included 60 patients with advanced larynx carcinoma who had received treatment and follow-up for at least 5 years. Sixty laryngeal carcinoma specimens and metastatic lymph nodes from 24 patients were examined for immunohistochemical PCNA expression.

Results: The percentages of PCNA positive cells were significantly higher in the primary tumours which developed lymph node metastases than in those without metastases. The fraction of PCNA immunolabelled cells in metastatic lymph nodes increased significantly when compared with the PCNA positive cell score in their corresponding primary tumours obtained from the same patient. There was a significant difference in PCNA index score in primary tumours between the group of patients who survived a 5 -year period and those who died within 5 years after treatment.

Conclusions: Our data demonstrate that a high proliferation index in primary larynx tumours is retained and increased in corresponding lymph node metastases. Measurement of the fraction of cancer cells stained for PCNA in primary larynx carcinomas can be helpful in selecting tumours with high aggressiveness potential that are more likely to develop neck metastases and thereby in identifying patients who need elective lymph node dissection or additional treatment.
\end{abstract}

Key words: proliferating cell nuclear antigen, larynx cancer, metastases.

\section{Introduction}

Predicting the outcome of laryngeal cancer is of utmost importance for the physician to decide on the treatment modality. Detection of a lymph node metastasis is the crucial factor in evaluating the necessity of neck dissection and the extent of surgery in patients with advanced laryngeal
Corresponding author: Andrzej Stepulak Department of Biochemistry and Molecular Biology Medical University Chodźki 1, 20-093 Lublin, Poland

Phone/fax: +48 817423793 E-mail: a12322@op.pl 
carcinomas. Clinical examination and imaging investigations of lymph node metastases such as computed tomography (CT) and magnetic resonance imaging (MRI) are helpful in the diagnostic process, but they are associated with false-positive or false-negative results [1-3]. Thus, additional parameters of the tumour to predict its more aggressive potential are needed, among them immunohistological analysis. Although different histological tumour biomarkers are not direct factors in predicting the occurrence of lymph node metastases, their evaluation could help categorize primary tumours with clinically more aggressive potential.

One of the most important criteria that show aggressive biological behaviour is the cellular proliferation rate of the tumour. Cell proliferation in a retrospective study involving archival material is mainly measured by means of immunohistochemical expression of $\mathrm{Ki}-67$ protein and proliferating cell nuclear antigen (PCNA) $[4,5]$. Proliferating cell nuclear antigen is a DNA polymerase-associated protein needed for DNA replication and repair [6]. Proliferating cell nuclear antigen appears in late G1 phase, increases during $S$ phase, and declines during $G 2$ and $M$ phases of the cell cycle [7], and is a potential biomarker of a variety of tumours [8-10], including laryngeal carcinomas [11-17]. The fraction of PCNA positive

Table I. Patient characteristics

\begin{tabular}{|c|c|}
\hline Characteristic & Number of patients \\
\hline Total number & 60 \\
\hline Median age (range) & $55(34-77)$ \\
\hline Male/female & $57 / 3$ \\
\hline \multicolumn{2}{|l|}{ Tumour grading: } \\
\hline - well differentiated (G1) & 10 \\
\hline - moderately differentiated (G2) & 37 \\
\hline - poorly differentiated (G3) & 13 \\
\hline \multicolumn{2}{|l|}{ TNM classification: } \\
\hline$\cdot \mathrm{T} 2$ & 8 \\
\hline$\cdot \mathrm{T} 3$ & 34 \\
\hline$\bullet \mathrm{T} 4$ & 18 \\
\hline - NO & 32 \\
\hline - N1 & 6 \\
\hline - N2 & 15 \\
\hline - N3 & 7 \\
\hline \multicolumn{2}{|l|}{ Clinical stage: } \\
\hline$\bullet \|$ & 7 \\
\hline$\bullet$ - III & 23 \\
\hline$\bullet \mathrm{IV}$ & 30 \\
\hline
\end{tabular}

cells progressively increases with the degree of epithelial hyperplasia in the larynx $[18,19]$, and inversely correlates with the degree of differentiation in larynx cancer $[14,15,20]$. The ratio of PCNA positive cells was also related to the occurrence of nodal metastases [11-14, 17] and PCNA immunolabelling in biopsy specimens was useful in identifying patients with clinically negative lymph nodes who were at considerable risk of occult metastases and may benefit from elective neck dissection [15]. However, these results are in contradiction to other reports showing no association between PCNA expression and presence of neck metastases [20-22]. Although several studies have implicated factors measuring cell proliferation in laryngeal tumours, only one has examined their expression in metastatic deposits [15]. Because therapy is also targeted toward metastatic disease, the assumption is made that expression of the tumour marker in secondary lesions reflects the situation observed in the primary tumour. To investigate this suggestion, the present study has evaluated the expression of the PCNA antigen in primary laryngeal carcinomas and their corresponding lymph node metastases in order to identify tumours which are more likely to metastasize.

\section{Material and methods}

\section{Patients}

The study included 60 patients, who were diagnosed with laryngeal cancer and underwent surgical treatment. Of these patients, 15 required total laryngectomies (TL), 11 total laryngectomies followed by radiotherapy (TL/RD), 12 total laryngectomies and functional neck dissection (TL/ND), and 22 total laryngectomies and radical neck dissection followed by radiotherapy (TL/ND/RD). Patient data are summarized in Table I.

\section{Slide preparation and section analysis}

Paraffin-embedded $4.5 \mu \mathrm{M}$ thin sections were stained with haematoxylin and eosin and assessed histopathologically. Immunohistochemical analysis of proliferating cell nuclear antigen was performed on 60 laryngectomy specimens and on 24 lymph node metastasis specimens using the avidin-biotinperoxidase technique. In brief, specimens were dewaxed with xylene, dehydrated in ethanol and incubated in 3\% hydrogen peroxide for $5 \mathrm{~min}$ to exhaust endogenous peroxidase activity. Epitope unmasking was performed using 0.1\% trypsin, $0.1 \%$ $\mathrm{CaCl}_{2}$ and $0.05 \mathrm{M}$ Tris solution ( $\mathrm{pH}$ 7.6) for $20 \mathrm{~min}$ at room temperature. After blocking in normal bovine serum, tissue sections were incubated with $1: 100$ diluted monoclonal PC10 antibody (Dako, Glostrup, Denmark). Biotynylated rabbit anti-mouse 
immunoglobulin (Dako, Glostrup, Denmark) was diluted $1: 300$ and used as a secondary antibody.

Proliferating cell nuclear antigen expression was assessed in tumour areas showing the highest density of staining, as determined by an initial scan at a magnification of 40x. For PCNA index counting, at $200 \times$ the field in each of the most stained areas was counted and the average count determined. The growth fraction by PCNA staining was evaluated by counting 500 consecutive cells for each tumour and an index of positive cells to total number of cells was scored. All pathological material was reviewed by two pathologists without knowledge of the clinical outcome and other clinicopathological features. Because of the PCNA scoring discrepancy between pathologists, samples of lymph node metastases from 4 patients were removed from the study.

\section{Statistical analysis}

Proliferating cell nuclear antigen immunostaining values (mean \pm SD) were compared with clinicopathological factors by means of ANOVA test, paired Student's $t$-test, and Pearson's correlation test. A value of $p<0.05$ was considered to be statistically significant.

\section{Results}

Proliferating cell nuclear antigen index in primary tumours and lymph node metastases

Positive PCNA immunostaining was found in all 60 larynx tumours and all analyzed lymph node metastases from 24 patients. The PCNA index in laryngeal carcinoma ranged from 15.8 to $73.0 \%$ and from 50.4 to $87.4 \%$ in lymph node metastases. The percentages of PCNA positive cells were significantly higher in the primary tumours associated with lymph node metastases than in those without metastases (Table II). We also analyzed the degree of cell proliferation directly in metastatic lymph nodes of 24 patients. The fraction of PCNA stained cells in metastatic lymph nodes increased significantly when compared with the PCNA positive cell score in their corresponding primary tumours as calculated by means of paired Student's $t$-test $(p<0.001)$ and Pearson's correlation test $(p=0.011)$. Mean index of PCNA positive cells was $69.97 \pm 10.09 \%(n=24)$ in metastases vs. 50.27 $\pm 12.89 \%(n=28)$ in primary tumours which developed metastases.

\section{PCNA score and TNM/clinical classification}

Clinical stage of neoplastic disease is often characterized by TNM classification. In our study the mean PCNA proliferation index was the highest in advanced larynx cancers classified as clinical
TNM stage IV, and decreased in tumours obtained from patients with clinical TNM stages III and II of the disease. ANOVA test analysis revealed that differences between these three values were statistically significant. There was no significant association between mean proliferation rate and T stage.

Proliferating cell nuclear antigen index and histological grade of the tumour

There was also a significant inverse correlation between PCNA mean proliferation index in primary larynx carcinoma and histological grade measured by means of ANOVA test. Mean score of PCNA positive cells was highest in poorly differentiated (G3) carcinomas, decreased in moderately differentiated (G2) carcinomas, and was the lowest in well differentiated (G1) carcinomas (Table II).

Proliferating cell nuclear antigen score and overall survival rate

We observed that mean PCNA index in primary tumours was lower in patients who survived a 5 -year period (Table II). However, having analyzed the PCNA score in connection with different treatment modalities, such a correlation was found only in the group of patients that underwent total

Table II. Correlation between PCNA index and pathological parameters in patients with larynx cancer

\begin{tabular}{|c|c|c|c|}
\hline Factor & $\begin{array}{c}\text { PCNA index } \\
\text { (\% positive cells) } \\
\text { in primary tumours }\end{array}$ & $\begin{array}{l}\text { Number } \\
\text { of patients }\end{array}$ & $p$ Value \\
\hline \multicolumn{4}{|c|}{ Tumour grading: } \\
\hline - G1 & $31.63 \pm 11.06$ & 10 & 0.006 \\
\hline - G2 & $45.01 \pm 15.64$ & 37 & \\
\hline - G3 & $51.43 \pm 12.03$ & 13 & \\
\hline \multicolumn{4}{|l|}{ T stage: } \\
\hline - T2 & $36.88 \pm 23.66$ & 8 & 0.33 \\
\hline$\cdot \mathrm{T3}$ & $44.70 \pm 12.99$ & 34 & (NS) \\
\hline - T4 & $46.44 \pm 15.18$ & 18 & \\
\hline \multicolumn{4}{|c|}{ Presence of lymph node metastases: } \\
\hline - NO & $38.84 \pm 15.54$ & 32 & 0.003 \\
\hline - N1-3 & $50.27 \pm 12.89$ & 28 & \\
\hline \multicolumn{4}{|c|}{ Clinical stage: } \\
\hline$\cdot$ - II & $31.84 \pm 20.39$ & 7 & 0.036 \\
\hline$\cdot$ - III & $42.95 \pm 13.64$ & 23 & \\
\hline - IV & $47.98 \pm 15.37$ & 30 & \\
\hline \multicolumn{4}{|c|}{ 5-year survival: } \\
\hline - alive & $39.23 \pm 16.06$ & 26 & 0.025 \\
\hline - died & $48.11 \pm 13.77$ & 34 & \\
\hline
\end{tabular}


Table III. Correlation between PCNA index in primary larynx tumour, treatment modality and 5-year survival period

\begin{tabular}{|c|c|c|c|c|c|}
\hline \multirow{3}{*}{$\begin{array}{l}\text { Treatment } \\
\text { modality }\end{array}$} & \multicolumn{5}{|c|}{ PCNA index in primary larynx tumour } \\
\hline & \multicolumn{2}{|c|}{$\begin{array}{l}\text { Patients survived } \\
5 \text { years }\end{array}$} & \multicolumn{2}{|c|}{$\begin{array}{l}\text { Patients died } \\
\text { within } 5 \text { years }\end{array}$} & \multirow{2}{*}{$\begin{array}{c}\begin{array}{c}\text { Statistical } \\
\text { significance }\end{array} \\
p=0.0813, \mathrm{~ns}\end{array}$} \\
\hline & $383.7 \pm 38.73$ & $(n=11)$ & $521.3 \pm 60.61$ & $(n=4)$ & \\
\hline $\mathrm{TL}+\mathrm{RD}(n=11)$ & $318.6 \pm 55.58$ & $(n=5)$ & $571.2 \pm 65.59$ & $(n=6)$ & $p=0.0186^{*}$ \\
\hline $\mathrm{TL}+\mathrm{ND}(n=12)$ & $432.2 \pm 63.43$ & $(n=5)$ & $483.9 \pm 57.21$ & $(n=7)$ & $p=0.5565, \mathrm{~ns}$ \\
\hline $\mathrm{TL}+\mathrm{ND}+\mathrm{RD}(n=22)$ & $481.8 \pm 129.1$ & $(n=5)$ & $504.3 \pm 29.17$ & $(n=17)$ & $p=0.7930, \mathrm{~ns}$ \\
\hline
\end{tabular}

$T L$ - total laryngectomy, $R D$ - radiotherapy, ND - neck dissection, (Student's $t$-test, ${ }^{*} p<0.05, n s-$ not significant)

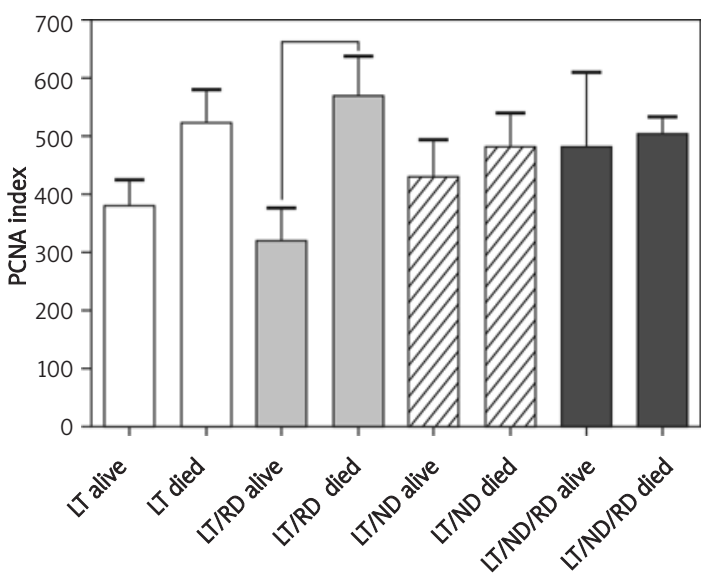

Figure 1. Correlation between PCNA index in primary larynx tumour, treatment modality and 5-year survival period

$T L$ - total laryngectomy, $R D$ - radiotherapy, ND - neck dissection, ${ }^{*} p<0.05$, Student's t-test

laryngectomy followed by radiotherapy $(p<0.05)$. A similar relationship was observed in patients who received other treatments but it was not statistically significant (Table III, Figure 1).

\section{Discussion}

Detection or prediction of the occurrence of lymph node metastases in patients with larynx cancer is a crucial step in the assessment of advancement of the disease state, which influences further therapeutic strategy and clinical outcome.

In general, high proliferative activity in larynx cancer is associated with a worse clinical outcome, including recurrence, shorter survival time and presence of metastases. However, the majority of performed studies analyzed the Ki-67 or PCNA proliferation indices only in primary cancers and then correlated these values with the occurrence of neck metastases [11-13, 16, 17, 20-22]. Very rare are reports where the authors assessed the degree of cell proliferation directly in lymph node metastases. In one of such studies the number of analyzed cases was limited to 10 lymph nodes derived from patients with laryngeal and hypopharyngeal cancers [15]. In our study, we performed an analysis of PCNA expression in lymph node metastases obtained from 24 patients who developed exclusively laryngeal carcinoma. We have noted a very high percentage of PCNA positive cells in all single metastasis specimens - the lowest score was over $50 \%$ of total cells and mean PCNA index was near $70 \%$ in metastatic lymph node samples. Paired t-test and Pearson's correlation test showed a positive correlation between increased PCNA index in metastases and lower PCNA index in corresponding primary carcinoma obtained from the same patient. Liu et al. [15] reported similar results, demonstrating higher PCNA index in metastases than in primary carcinomas. Additionally, we have shown that laryngeal tumours associated with neck metastases were characterized by increased PCNA index when compared with tumours without lymph node metastases, which is consistent with a great number of studies [11-17] and in contradiction to only a few reports [20-22]. It is plausible that metastasizing laryngeal carcinomas could develop a cell population with highly proliferative potential, and this potential is retained in arising metastases. Although PCNA is not directly involved in the metastatic behaviour of cancer cells, it could be a good prognosticator for the selection of tumours which are prone to metastasis.

Increased cell proliferation is regarded as one of the most important biological mechanisms in oncogenesis. Proliferating cell nuclear antigen expression is often associated with other proteins involved in cell cycle progression. A positive correlation between PCNA expression and overexpression of cyclin-dependent kinase 2 (CDK2) [23], cyclin A [24], cyclin E [25], cyclin-dependent kinase 4 (CDK4) and cyclin D1 [26] has been found in laryngeal carcinoma, which indicates a close association between PCNA expression and proliferation activity of tumour cells. The property of cell proliferation is related to the progression of various malignancies and influences disease-free and overall survival $[4,10,14]$. In our study we demonstrated that mean PCNA index is negatively correlated with 5-year survival rate in the group of patients who underwent total laryngectomy 
followed by radiotherapy. This tendency was also shown in the group of patients that received other treatment modalities, although the differences were not significant and decreased according to more aggressive therapy applied (LT/RD vs. LT/ND vs. LT/ND/RD), which was also connected with increasing clinical stage of the disease. Since patients were qualified for different treatment modalities according to clinical examinations, histological type and grading of the primary tumour, and imaging investigations (CT, occasionally also lymphoscintigraphy), the type of treatment was dependent on clinical stage of the neoplastic disease. Therefore differences between PCNA scores measured in the group of patients who survived and those who died within a 5-year period and received the same therapy could to some extent reflect the proliferation potency of larynx tumours; however, they are greatly influenced by the local progression of the neoplastic disease. The PCNA index assessment was more prognostic in the group of patients with less advanced disease who also received less aggressive therapy. The high PCNA score found in this group of patients should draw our attention to considering more aggressive therapy

Several studies have reported increased proliferative indices associated with tumour grade $[14,16,20,21]$. The grade of laryngeal carcinoma was an important factor affecting recurrence [27], and thereby together with biological markers reflecting tumour proliferation potential could be useful for the detection of tumours that require more aggressive treatment [28]. We observed an inverse correlation between PCNA index and tumour grading. These findings are consistent with some studies $[14,16,20,21]$ and in contradiction to others [12, 22]. More detailed histological examinations showed that PCNA immunostaining corresponds to the histological grade of benign epithelial hyperplastic lesions and squamous cell carcinoma of the larynx [18, 19]. In well differentiated, keratinizing carcinomas, PCNA staining was observed in layers adjacent to the basal membrane at the periphery of the tumour islands, while in less differentiated, non-keratinizing carcinomas, the number of PCNA positive cells increased and they tended to be dispersed throughout the sample [19]. It was also reported that immunostaining of PCNA was heterogeneous within each laryngeal carcinoma and varied widely between tumours [14], which could be responsible for the observed discrepancy between different reports.

Despite these practical limitations, the pretherapeutic assessment of PCNA expression may become of increasing importance in the evaluation of tumour aggressiveness and of prognostic value in predicting neck metastases in patients with laryngeal carcinoma, especially when analyzed in preoperative biopsy specimens [15].

In conclusion, our data demonstrate that a high proliferation index in primary larynx tumours is retained and increased in corresponding lymph node metastases. The measurement of the fraction of cancer cells stained for PCNA in the primary larynx carcinomas can be helpful in selecting tumours with high aggressiveness potential that are more likely to develop neck metastases, and thereby in identifying patients who need elective lymph node dissection or additional treatment.

\section{References}

1. Anzai Y, Brunberg JA, Lufkin RB. Imaging of nodal metastases in the head and neck. J Magn Reson Imaging 1997; 7: 774-83.

2. Galioto GB, Mevio E, Benazzo M, et al. Prognostic parameters in metastatic spread of laryngeal cancer: clinico-histopathological correlations. Clin Otolaryngol Allied Sci 1987; 12: 303-8.

3. Kau RJ, Alexiou C, Stimmer H, et al. Diagnostic procedures for detection of lymph node metastases in cancer of the larynx. ORL J Otorhinolaryngol Relat Spec 2000; 62: 199-203.

4. Pich A, Chiusa L, Navone R. Prognostic relevance of cell proliferation in head and neck tumors. Ann Oncol 2004; 15: 1319-29.

5. Scholzen T, Gerdes J. The Ki-67 protein: from the known and the unknown. J Cell Physiol 2000; 182: 311-22.

6. Jonsson ZO, Hubscher U. Proliferating cell nuclear antigen: more than a clamp for DNA polymerases. Bioessays 1997; 19: 967-75.

7. Mathews MB, Bernstein RM, Franza BR Jr., et al. Identity of the proliferating cell nuclear antigen and cyclin. Nature 1984; 309: 374-6.

8. Kimos MC, Wang S, Borkowski A, et al. Esophagin and proliferating cell nuclear antigen (PCNA) are biomarkers of human esophageal neoplastic progression. Int J Cancer 2004; 111: 415-7.

9. Taftachi R, Ayhan A, Ekici S, et al. Proliferating-cell nuclear antigen (PCNA) as an independent prognostic marker in patients after prostatectomy: a comparison of PCNA and Ki-67. BJU Int 2005; 95: 650-4.

10. Wang JL, Zheng BY, Li XD, et al. Predictive significance of the alterations of p16INK4A, p14ARF, p53, and proliferating cell nuclear antigen expression in the progression of cervical cancer. Clin Cancer Res 2004; 10: 2407-14.

11. Boran C, Yildiz L, Kandemir B, et al. Correlation of proliferating cell nuclear antigen and bcl-2 expression with tumor front grading and metastasis in laryngeal squamous cell carcinoma. Neoplasma 2003; 50: 139-43.

12. Dobros W, Rys J, Niezabitowski A, et al. The prognostic value of proliferating cell nuclear antigen (PCNA) in the advanced cancer of larynx. Auris Nasus Larynx 1998; 25: 295-301.

13. Franchi A, Gallo O, Boddi V, et al. Prediction of occult neck metastases in laryngeal carcinoma: role of proliferating cell nuclear antigen, MIB-1, and E-cadherin immunohistochemical determination. Clin Cancer Res 1996; 2: 1801-8.

14. Liu M, Lawson G, Delos M, et al. Prognostic value of cell proliferation markers, tumour suppressor proteins and 
cell adhesion molecules in primary squamous cell carcinoma of the larynx and hypopharynx. Eur Arch Otorhinolaryngol 2003; 260: 28-34.

15. Liu M, Lawson G, Delos M, et al. Predictive value of the fraction of cancer cells immunolabeled for proliferating cell nuclear antigen or Ki67 in biopsies of head and neck carcinomas to identify lymph node metastasis: comparison with clinical and radiologic examinations. Head Neck 2003; 25: 280-8.

16. Liu M, Lawson G, Delos M, et al. Evaluation of proliferating cell nuclear antigen (PCNA) in supraglottic carcinoma. Acta Otorhinolaryngol Belg 1997; 51: 129-35.

17. Sarac S, Ayhan A, Hosal AS, et al. Prognostic significance of PCNA expression in laryngeal cancer. Arch Otolaryngol Head Neck Surg 1998; 124: 1321-4.

18. Laitakari J, Harrison D, Stenback F. Automated image analysis of proliferating cells in carcinoma of the larynx. Acta Otolaryngol 2003; 123: 759-66.

19. Zidar N, Gale N, Cor A, et al. Expression of Ki-67 antigen and proliferative cell nuclear antigen in benign and malignant epithelial lesions of the larynx. J Laryngol Otol 1996; 110: 440-5.

20. Morawski K, Gabriel A, Namyslowski G, et al. Clinical application of proliferating cell nuclear antigen, oncoprotein p53 and tumor front grading analysis in patients operated on for laryngeal cancer. Eur Arch Otorhinolaryngol 1999; 256: 378-83.

21. Bayazit Y, Bakir K, Ucak R, et al. Clinical and histopathological correlates of the proliferative activity in squamous cell laryngeal carcinoma. Rev Laryngol Otol Rhinol (Bord) 2002; 123: 43-6.

22. Grzanka A, Sujkowska R, Janiak A, et al. Immunogold labelling of PCNA and Ki-67 antigen at the ultrastructural level in laryngeal squamous cell carcinoma and its correlation with lymph node metastasis and histological grade. Acta Histochem 2000; 102: 139-49.

23. Dong Y, Sui L, Tai Y, et al. The overexpression of cyclindependent kinase (CDK) 2 in laryngeal squamous cell carcinomas. Anticancer Res 2001; 21: 103-8.

24. Dong Y, Sui L, Watanabe Y, et al. Aberrant expression of cyclin A in laryngeal squamous cell carcinoma. Anticancer Res 2002; 22: 83-9.

25. Dong Y, Sui L, Tai Y, et al. Prognostic significance of cyclin E overexpression in laryngeal squamous cell carcinomas. Clin Cancer Res 2000; 6: 4253-8.

26. Dong Y, Sui L, Sugimoto K, et al. Cyclin D1-CDK4 complex, a possible critical factor for cell proliferation and prognosis in laryngeal squamous cell carcinomas. Int J Cancer 2001; 95: 209-15.

27. Buyukbayram H, Cureoglu S, Arslan A, et al. Prognostic value of PCNA and mutant p53 expression in laryngeal squamous cell carcinoma. Cancer Invest 2004; 22 : 195-202.

28. Jacob R, Welkoborsky HJ, Bittinger F, et al. Histological grading, growth fraction and DNA-ploidy as criteria for the treatment of pharyngeal and supraglottic squamous cell carcinomas: a preliminary, prospective study. ORL J Otorhinolaryngol Relat Spec 2001; 63: 314-20. 